\title{
TESTE DE ENVELHECIMENTO ACELERADO PARA AVALIAÇÃO DA QUALIDADE DE SEMENTES DE ALFACE E ALMEIRÃO ${ }^{1}$
}

\author{
FRANCIELE DOS SANTOS ${ }^{2}$, PAULO ESPÍNDOLA TRANI ${ }^{3}$, \\ PRISCILA FRATIN MEDINA ${ }^{4}$, JOÃO JOSÉ DIAS PARISI ${ }^{5}$
}

\begin{abstract}
RESUMO - O uso de testes de vigor para avaliação da qualidade dos lotes de sementes é uma ferramenta imprescindível para produção e comercialização. No entanto, para sementes de alface e almeirão as pesquisas relacionadas à avaliação de sua qualidade ainda são escassas. Para sementes de alface, apenas o teste de germinação é considerado padronizado, enquanto os demais devem ser aprimorados visando fornecer informações mais precisas. Com intuito de adequar a metodologia do teste de envelhecimento acelerado para avaliar a qualidade de lotes de sementes de alface e almeirão, foram utilizados quatro lotes de sementes de alface das cultivares Maravilha e Verdinha e quatro lotes de sementes de almeirão das cultivares Catalonha e Pão-de-Açúcar. Na condução do teste de envelhecimento acelerado as sementes foram submetidas ao envelhecimento tradicional, e ao envelhecimento com solução saturada e diluída de $\mathrm{NaCl}$; usaram-se três períodos distintos: 48, 72 e 96 horas. Para caracterizar a qualidade dos lotes foi determinado o grau de umidade das sementes, e realizados os testes de germinação, primeira contagem de germinação e emergência de plântulas em casa de vegetação. Concluiu-se que o teste de envelhecimento acelerado aos $41^{\circ} \mathrm{C}$ possibilita a separação dos lotes em diferentes níveis de vigor, podendo ser utilizado em sementes de alface e almeirão, considerando-se o período de envelhecimento de 48 horas pelo método tradicional ou o de 72 horas pelo método com solução saturada de $\mathrm{NaCl}$. Quanto ao método modificado pelo uso da solução diluída de $\mathrm{NaCl}$, o período de 48 horas é adequado para as sementes de alface e o de 72 horas, para as de almeirão.
\end{abstract}

Termos para indexação: Lactuca sativa, Cichorium intybus, vigor, estabelecimento de plântulas.

\section{ACCELERATED AGING TEST FOR EVALUATING LETTUCE AND ENDIVE SEED QUALITY}

\begin{abstract}
The use of vigor tests for assessing seed lot quality is an important tool for production and commercialization. However, research on evaluating the quality of lettuce and endive seeds is still scarce since only the germination test is considered as standardized for lettuce seeds and other tests must be improved to obtain more accurate information. In order to adapt the methodology of the accelerating aging tests to evaluate the quality of lettuce and endive seed lots, four seeds lots of 'Maravilha' and 'Verdinha' lettuce cultivars and four seeds lots of 'Catalonha' and 'Pãode-Açúcar' endive cultivars were used. In the accelerated aging test, the seeds were submitted to
\end{abstract}

\footnotetext{
${ }^{1}$ Submetido em 30/09/2010. Aceito para publicação em 22/11/2010. Parte do Relatório de Estágio Curricular Profissionalizante do primeiro autor apresentado a UNESP - Campus de Registro.
}

${ }^{2}$ Eng. Agr., Mestranda do Programa tecnologia da Produção Agrícola, Instituto Agronômico de Campinas, Caixa Postal, 28, 13012-970, Campinas/SP, f_dsantos@hotmail.com.

${ }^{3}$ Eng. Agr., Dr., Pesquisador Científico do Instituto Agronômico de
Campinas, Centro de Horticultura, petrani@iac.sp.gov.br.

${ }^{4}$ Eng. Agr., Dr., Pesquisador Científico do Instituto Agronômico de Campinas, Laboratório de Análise de Sementes, pfmedina@iac.sp.gov.br.

${ }^{5}$ Eng. Agr., Dr., Pesquisador Científico do Instituto Agronômico de Campinas, Centro de Pesquisa e Desenvolvimento de Fitossanidade, jparisi@iac.sp.gov.br. 
the traditional aging method and to aging with a saturated and diluted $\mathrm{NaCl}$ solution for 48, 72 and 96 hours. To characterize seed lot quality, the seed moisture content was determined and the germination test, first germination count and seedling emergence in the greenhouse were verified. It was concluded that the accelerated aging test allows the separation of seeds lots into different vigor levels. The 48-hour aging period can be used with the traditional method and the 72-hour period for the saturated $\mathrm{NaCl}$ solution for both lettuce and endive seeds. Considering the method using a diluted $\mathrm{NaCl}$ solution, the best periods were 48 hours for lettuce seeds and 72 hours for endive seeds.

Índex terms: Lactuca sativa, Cichorium intybus, vigor, stand establishment.

\section{INTRODUÇÃO}

A avaliação do potencial fisiológico de sementes constitui um componente fundamental nos programas de controle de qualidade das empresas produtoras ou para caracterizar as sementes destinadas à comercialização (Ávila et. al, 2006). No caso, das sementes de hortaliças, como alface e almeirão, a pesquisa ainda não estabeleceu procedimentos apropriados para avaliação do vigor, o que limita a disponibilização de lotes de boa qualidade. Para as sementes de alface apenas o teste de germinação está completamente padronizado (Franzin et. al, 2004), e para sementes de almeirão trabalhos científicos envolvendo qualidade fisiológica ainda são escassos tanto no Brasil quanto no exterior (Carvalho e Nakagawa, 2000).

Para averiguar os componentes da qualidade das sementes são realizados testes como o de germinação, que por ser conduzido em condições favoráveis de umidade e temperatura, geralmente superestima o potencial fisiológico dos lotes de sementes, sendo, portanto, cada vez maior a necessidade do uso e aprimoramento de testes de vigor. Vários trabalhos de pesquisa na área de sementes têm se concentrado em estudar esses testes, na tentativa de identificar aqueles com maior sensibilidade e eficiência para diferenciar os lotes quanto ao nível de vigor.

O teste de envelhecimento acelerado é um dos testes de vigor mais utilizados por a fornecer resultados que se relacionam tanto com o potencial relativo de armazenamento dos lotes de sementes quanto com a emergência das plântulas em campos de produção agrícola (TeKrony, 1995). Este teste tem como princípio a aceleração artificial da taxa de deterioração das sementes, expondo-as em níveis elevados de temperatura e umidade relativa do ar, considerados os fatores ambientais preponderantes na intensidade e velocidade de deterioração (Marcos Filho, 1999). Consequentemente, o teste de envelhecimento pode ser considerado como um dos mais sensíveis para a avaliação do vigor de sementes, dentre os disponíveis (Marcos Filho, 1999), pois seus resultados se relacionam com o potencial de conservação das sementes.

Diversos são os fatores que afetam o comportamento das sementes durante o teste. A interação temperatura/ período de exposição é um dos mais pesquisados. Outro fator importante relaciona-se com as diferenças na absorção de água pelas sementes quando expostas à atmosfera úmida no teste de envelhecimento acelerado. Essas diferenças podem acarretar variações acentuadas no teor de água das mesmas. Para Powell (1995) alguns estudos conduzidos com espécies de sementes relativamente pequenas, como as de hortaliças, têm apresentado resultados menos consistentes devido à variação muito acentuada no grau de umidade ao final do período de envelhecimento. Sementes pequenas absorvem água de forma mais rápida e desuniforme, em relação às sementes maiores, durante o período de envelhecimento, o que pode acelerar o processo de deterioração ou apresentar variação de dados entre as sementes de uma mesma amostra, interferindo na precisão dos resultados (Jianhua e McDonald, 1997; Bhéring et al., 2006).

Em função disso, procedimentos alternativos vêm sendo estudados para a condução desse teste, substituindose a água por igual volume de soluções saturadas de sais, 
optando-se por $\mathrm{KCl}$ ( $87 \% \mathrm{UR}), \mathrm{NaCl}$ ( $76 \% \mathrm{UR})$ ou $\mathrm{NaBr}$ (55\% UR). Dependendo da solução utilizada podem ser obtidas umidades relativas inferiores às verificadas no envelhecimento convencional, fazendo com que a absorção de água pelas sementes ocorra em menor intensidade e de forma mais lenta e uniforme, culminando numa menor intensidade de deterioração e menor variação entre os resultados (Jianhua e McDonald, 1997).

Embora esse teste venha sendo amplamente estudado visando sua padronização para muitas espécies, as informações são mais escassas para as sementes de hortaliças quando comparadas às das grandes culturas. Neste sentido, a referida pesquisa teve como objetivo verificar a eficiência do teste de envelhecimento acelerado quanto à identificação de diferenças entre níveis de vigor de lotes de sementes de alface e de almeirão e estabelecer uma metodologia adequada para a sua condução.

\section{MATERIAL E MÉTODOS}

O experimento foi conduzido no Laboratório de Análise de Sementes do Centro de Pesquisa e Desenvolvimento de Fitossanidade e no Campo Experimental do Centro de Horticultura, situados no Instituto Agronômico de Campinas (IAC). Foram utilizados quatro lotes de sementes de alface (Lactuca sativa L.), das cultivares Maravilha das Quatro Estações e Verdinha, provenientes do Centro de Horticultura; e quatro lotes de sementes de almeirão (Cichorium intybus L.), das cultivares Catalonha e Pão-de-Açúcar, fornecidas pela empresa SAKATA S.A. Para verificar a eficiência dos métodos propostos para identificação de diferentes níveis de vigor dos lotes estudados, foram realizados os seguintes testes: Grau de umidade, determinado pelo método em estufa aos $105 \pm 3{ }^{\circ} \mathrm{C}$, por 24 horas (Brasil, 2009), utilizando-se duas subamostras por lote, pesando aproximadamente 5,0 g de sementes por amostra.

Para a realização do teste de germinação foram empregadas quatro repetições de 50 sementes por lote. As sementes foram distribuídas sobre duas folhas de papel mata-borrão, umedecidas com quantidade de água destilada equivalente a 2,5 vezes o peso do substrato seco e colocadas para germinar aos $20^{\circ} \mathrm{C}$, na presença de luz constante. As avaliações foram realizadas aos quatro e sete dias após a semeadura para a cultura de alface, e aos cinco e quatorze dias para a cultura de almeirão (Brasil, 2009). Os resultados foram expressos em porcentagem média de plântulas normais para cada lote.
Os dados referentes primeira contagem de germinação foram obtidos computando-se a porcentagem média de plântulas normais verificadas aos quatro dias após a instalação do teste de germinação para as sementes de alface, e aos cinco dias após a semeadura para as sementes de almeirão. Os resultados foram expressos em porcentagem média de plântulas normais para cada lote.

O teste de envelhecimento acelerado foi conduzido utilizando-se caixas plásticas transparentes (11,5x11,5x3,5 $\mathrm{cm}$ ) como compartimentos individuais (mini-câmaras), possuindo em seu interior suportes para apoio de uma tela metálica. Na superfície de cada uma destas, após a pesagem (aproximadamente 1,5 g) as sementes foram distribuídas de maneira a formar uma camada uniforme. Para condução do teste de envelhecimento acelerado foram adicionados ao fundo de cada caixa plástica: a) $40 \mathrm{~mL}$ de água destilada (Costa et al., 2008) estabelecendo um ambiente com 100\% de umidade relativa do ar; b) $40 \mathrm{~mL}$ de solução saturada de $\mathrm{NaCl}$ (40 g de $\mathrm{NaCl}$ por $100 \mathrm{~mL}$ de água (Costa et al., 2008) estabelecendo um ambiente com $76 \%$ de umidade relativa do ar; e c) $40 \mathrm{~mL}$ de solução diluída de $\mathrm{NaCl}$ (11 g de $\mathrm{NaCl}$ por $100 \mathrm{~mL}$ de água (Costa et al., 2008) estabelecendo um ambiente com 94\% de umidade relativa do ar. As caixas foram tampadas e mantidas em câmaras de envelhecimento (tipo B.O.D) regulada aos $41{ }^{\circ} \mathrm{C}$, durante 48, 72 e 96 horas.

Decorrido cada período de envelhecimento, quatro subamostras de 50 sementes por tratamento foram colocadas para germinar, seguindo o procedimento utilizado para o teste de germinação. A avaliação foi realizada aos quatro dias após a semeadura para as sementes de alface e aos cinco dias para as sementes de almeirão, computando-se a porcentagem de plântulas normais. Foi determinado também, o grau de umidade das sementes, após cada período de envelhecimento, visando à avaliação da uniformidade das condições do teste.

Para a condução do teste de emergência de plântulas em casa de vegetação foram utilizadas quatro repetições de 50 sementes por lote, semeadas individualmente em bandejas de poliestireno com 200 células, contendo substrato comercial Plantmax HT®. As irrigações foram realizadas diariamente por sistema de microaspersão. A avaliação da emergência das plântulas foi efetuada aos sete dias após a semeadura para as sementes de alface e quatorze dias para as sementes de almeirão, mediante a contagem de plântulas normais emergidas, caracterizadas de acordo com critérios estabelecidos pelo teste de germinação. Os resultados foram expressos em 
porcentagem média de plântulas normais para cada lote.

O delineamento estatístico utilizado foi o inteiramente casualizado, com quatro repetições por tratamento, com exceção para determinação do grau de umidade das sementes, no qual foram usadas duas subamostras por lote. Os dados foram transformados em $\operatorname{arcsen}\left(x \cdot 100^{-1}\right)^{1 / 2}$, sendo submetidos à análise de variância e as médias foram comparadas pelo teste de Tukey, em 5\% de probabilidade, por meio do Sistema de Análise Estatística SISVAR, versão 4.6 para microcomputadores (Ferreira, 2003).

\section{RESULTADOS E DISCUSSÃO}

As diferenças na qualidade inicial dos lotes de sementes de alface e almeirão podem ser observadas pelos resultados dos testes de germinação, primeira contagem de germinação e de emergência de plântulas (Tabelas 1 e 2).

Verificou-se pelo teste de germinação que os lotes da cultivar de alface Maravilha das Quatro Estações não diferiram entre si. Com relação à cultivar Verdinha, o lote 3 foi considerado como de qualidade inferior, enquanto os lotes 1 e 2 foram agrupados no nível superior, não diferindo entre si e o lote 4 apresentou qualidade intermediária (Tabela 1). Para as cultivares de almeirão, os valores de germinação mostraram que para a cultivar Catalonha apenas o lote 4 foi significativamente superior aos lotes 1 e 2. Já para a cultivar Pão-de-Açúcar os resultados indicaram que ocorreu a superioridade estatística dos lotes 2 e 3 em comparação aos lotes 1 e 4 (Tabela 2).

TABELA 1. Dados médios expressos em porcentagem para os testes de germinação (TG), primeira contagem de germinação (PCG), emergência de plântulas (EP) e determinação do grau de umidade (GU), para sementes de alface, das cultivares Maravilha das Quatro Estações e Verdinha.

\begin{tabular}{cccccc}
\hline \multirow{2}{*}{ Cultivares } & Lotes & TG & PCG & EP & GU \\
\cline { 2 - 6 } & 1 & $92 \mathrm{a}$ & $84 \mathrm{~b}$ & $88 \mathrm{c}$ & 7,2 \\
& 2 & $92 \mathrm{a}$ & $88 \mathrm{a}$ & $95 \mathrm{a}$ & 7,4 \\
Maravilha & 3 & $92 \mathrm{a}$ & $82 \mathrm{c}$ & $91 \mathrm{~b}$ & 7,2 \\
& 4 & $91 \mathrm{a}$ & $82 \mathrm{c}$ & $91 \mathrm{~b}$ & 7,3 \\
\hline CV $(\%)$ & 1 & 97,2 & 4,7 & 5,3 & 7,7 \\
\hline \multirow{2}{*}{ Verdinha } & 2 & $97 \mathrm{a}$ & $96 \mathrm{a}$ & $92 \mathrm{a}$ & 7,5 \\
& 3 & $88 \mathrm{~b}$ & $71 \mathrm{c}$ & $85 \mathrm{~b}$ & 7,3 \\
\hline CV $(\%)$ & 4 & $95 \mathrm{ab}$ & $92 \mathrm{~b}$ & $85 \mathrm{~b}$ & 7,5 \\
\hline
\end{tabular}

Médias seguidas pela mesma letra na coluna não diferem entre si pelo teste de Tukey, $\mathrm{p} \leq 0,05$.

O teste de primeira contagem de germinação (Tabela 1) mostrou-se mais sensível que o de germinação, classificando os lotes em diferentes níveis de qualidade fisiológica. Para a cultivar Maravilha estas diferenças foram significativas; o lote 2 foi considerado como de melhor qualidade, e os lotes 3 e 4 como os de pior qualidade. Com relação aos lotes da cultivar Verdinha, esses apresentaram resultados semelhantes aos do teste de germinação, porém, a distribuição dos lotes em diferentes níveis de vigor foi mais nítida. Para os lotes de sementes de almeirão (Tabela 2) observou-se que para a cultivar Catalonha o lote 4 foi classificado como de melhor qualidade, embora não diferindo estatisticamente dos lotes 1 e 2, e o lote 3 foi identificado como de pior qualidade. No entanto, os resultados da primeira contagem de germinação classificaram os lotes de sementes da cultivar Pão-de-Açúcar de maneira semelhante aos dos resultados do teste de germinação. 
TABELA 2. Dados médios expressos em porcentagem para os testes de germinação (TG), primeira contagem de germinação (PCG), emergência de plântulas (EP) e determinação do grau de umidade (GU), para sementes de almeirão, das cultivares Catalonha e Pão-de-Açúcar.

\begin{tabular}{lccccc}
\hline \multirow{2}{*}{ Cultivares } & Lotes & TG & PCG & EP & GU \\
\cline { 2 - 6 } & & & & $\%$ & \\
& 1 & $92 \mathrm{~b}$ & $85 \mathrm{ab}$ & $90 \mathrm{~b}$ & 8,0 \\
Catalonha & 2 & $88 \mathrm{~b}$ & $85 \mathrm{ab}$ & $83 \mathrm{c}$ & 8,1 \\
& 3 & $93 \mathrm{ab}$ & $84 \mathrm{~b}$ & $97 \mathrm{a}$ & 8,1 \\
\hline CV (\%) & 4 & $99 \mathrm{a}$ & $86 \mathrm{a}$ & $95 \mathrm{a}$ & 8,2 \\
\hline \multirow{2}{*}{ Pão-de-Açúcar } & 1 & 3,4 & 2,6 & 6,1 & 7,9 \\
& 2 & $86 \mathrm{a}$ & $81 \mathrm{~b}$ & $88 \mathrm{~b}$ & 8,0 \\
& 3 & $86 \mathrm{a}$ & $89 \mathrm{a}$ & $92 \mathrm{a}$ & 7,8 \\
\hline CV (\%) & 4 & $82 \mathrm{~b}$ & $81 \mathrm{~b}$ & $86 \mathrm{c}$ & 7,9 \\
\hline
\end{tabular}

Médias seguidas pela mesma letra na coluna não diferem entre si pelo teste de Tukey, $\mathrm{p} \leq 0,05$.

Os resultados dos testes de emergência de plântulas, realizados em ambiente de casa de vegetação (Tabela 1), classificaram as sementes do lote 2 da cultivar de alface Maravilha como as de qualidade significativamente superior a dos demais e as do lote 1 como inferiores. Para a cultivar Verdinha o teste possibilitou a identificação da superioridade dos lotes 1 e 2 . Já para as sementes de almeirão (Tabela 2), o lote 2 da cultivar Catalonha foi identificado como o de pior desempenho, e os lotes 3 e 4 foram classificados como os mais vigorosos. Quanto à cultivar Pão-de-Açúcar, o lote 3 foi classificado como o de melhor qualidade fisiológica e o lote 4 apresentou o pior desempenho.

Comparando-se os dados obtidos, de uma maneira geral, os testes de vigor separaram, de modo consistente, diferenças acentuadas na qualidade fisiológica das sementes. Assim, pode-se afirmar que o lote 2 da cultivar de alface Maravilha era o mais vigoroso e os demais se revezaram como lotes de vigor intermediário ou de menor vigor e que os lotes 1 e 2 da 'Verdinha' eram mais vigorosos do que os lotes 3 e 4 . Para a cultivar de almeirão Pão-de-Açúcar, os lotes 1 e 4 apresentaram menor vigor e o lote 3 foi o de maior vigor e para a 'Catalonha' o lote 4 era o mais vigoroso, enquanto os demais se revezaram entre o comportamento intermediário ou de maior e menor vigor, ocupando posições diferentes de acordo com o teste utilizado. Isto, provavelmente ocorreu, porque a identificação de lotes de vigor intermediário pode sofrer variações em função da metodologia adotada, principalmente quando se tratam de lotes com germinação superior à mínima estabelecida para a comercialização.

Os dados referentes ao grau de umidade dos diferentes lotes, dentro de cada cultivar, não apresentaram variação acentuada (Tabelas 1 e 2). Este fato é importante para a execução dos testes, porque a uniformização do teor de água das sementes é imprescindível para a padronização das avaliações e obtenção de resultados comparáveis. No envelhecimento acelerado, a desuniformidade do teor de água nas sementes gera variação acentuada em sua intensidade de deterioração (Marcos Filho et al., 1987).

A avaliação do potencial fisiológico por meio do teste de envelhecimento acelerado mostrou que as sementes de alface envelhecidas pelo método tradicional apresentaram acréscimos no teor de água com o aumento do período de envelhecimento. Verificou-se que esse incremento foi mais acentuado no primeiro período de envelhecimento, ou seja, após 48 horas (Tabela 3). A partir deste período, o teor de água das sementes continuou aumentando, porém, em proporções inferiores. O teor de água das sementes expostas à solução saturada e diluída de $\mathrm{NaCl}$ apresentou valores menores e mais uniformes, após os períodos de envelhecimento em relação aos observados para as envelhecidas pelo procedimento tradicional (Tabela 3). Isto indica que o uso de solução salina contribui para retardar a absorção de água pelas sementes durante o envelhecimento das mesmas. Porém, mesmo no envelhecimento tradicional 
a maior variação de grau de umidade entre os lotes da mesma cultivar foram inferiores a 1\% e segundo Marcos Filho (1999), um dos principais indicadores da uniformidade das condições de envelhecimento acelerado é o grau de umidade das sementes ao final do teste, sendo que variações de 3 a 4\% entre amostras são consideradas toleráveis.

TABELA 3. Teor de água (TA) obtido após os períodos de envelhecimento, aos $41^{\circ} \mathrm{C}$, em sementes de alface, cultivares Maravilha das Quatro Estações e Verdinha.

\begin{tabular}{|c|c|c|c|c|c|c|c|c|c|c|}
\hline \multirow{3}{*}{ Cultivar } & \multirow{3}{*}{ Lotes } & \multicolumn{9}{|c|}{ TA (\%) } \\
\hline & & \multicolumn{3}{|c|}{$\mathrm{EA}^{1}$} & \multicolumn{3}{|c|}{$\mathrm{EA}^{2}$} & \multicolumn{3}{|c|}{$\mathrm{EA}^{3}$} \\
\hline & & $48 \mathrm{~h}$ & $72 \mathrm{~h}$ & $96 \mathrm{~h}$ & $48 \mathrm{~h}$ & $72 \mathrm{~h}$ & $96 \mathrm{~h}$ & $48 \mathrm{~h}$ & $72 \mathrm{~h}$ & $96 \mathrm{~h}$ \\
\hline \multirow{4}{*}{ Maravilha } & 1 & 25,3 & 30,4 & 32,5 & 8,5 & 8,1 & 15,3 & 10,6 & 10,0 & 11,8 \\
\hline & 2 & 25,1 & 31,0 & 32,4 & 8,4 & 8,2 & 15,2 & 10,7 & 10,2 & 11,8 \\
\hline & 3 & 25,1 & 30,3 & 32,5 & 8,2 & 8,4 & 14,9 & 10,4 & 10,4 & 11,5 \\
\hline & 4 & 25,2 & 30,4 & 32,5 & 8,2 & 8,4 & 14,9 & 10,4 & 10,3 & 11,6 \\
\hline \multirow{4}{*}{ Verdinha } & 1 & 25,0 & 21,5 & 25,4 & 7,0 & 6,9 & 11,8 & 8,0 & 8,5 & 7,9 \\
\hline & 2 & 25,1 & 21,4 & 25,6 & 7,1 & 7,0 & 11,8 & 8,1 & 8,4 & 8,0 \\
\hline & 3 & 25,3 & 21,3 & 25,6 & 7,3 & 6,9 & 11,5 & 8,2 & 8,4 & 8,1 \\
\hline & 4 & 25,1 & 21,3 & 25,7 & 7,3 & 7,0 & 11,7 & 8,2 & 8,5 & 8,1 \\
\hline
\end{tabular}

${ }^{1}$ Teste de envelhecimento acelerado seguindo a metodologia tradicional, com água; ${ }^{2}$ Teste de envelhecimento acelerado utilizando solução saturada de $\mathrm{NaCl} ;{ }^{3}$ Teste de envelhecimento acelerado utilizando solução diluída de $\mathrm{NaCl}$.

Verificou-se que todos os procedimentos de envelhecimento (Tabela 4) proporcionaram a identificação do lote 2 como o de maior vigor para a cultivar Maravilha; e para a cultivar Verdinha os lotes 1 e 2 como os de maior vigor e os lotes 3 e 4 como os de menor vigor. Nesse sentido, há concordância com o teste de primeira contagem de germinação para a 'Maravilha' e com os de primeira contagem de germinação e de emergência das plântulas em casa de vegetação para a 'Verdinha' (Tabela 1).

TABELA 4. Germinação de sementes de alface, das cultivares Maravilha das quatro estações e Verdinha, obtidas após teste de envelhecimento acelerado, aos $41^{\circ} \mathrm{C}$, com três períodos de exposição.

\begin{tabular}{|c|c|c|c|c|c|c|c|c|c|c|}
\hline \multirow{3}{*}{ Cultivar } & \multirow{3}{*}{ Lotes } & \multicolumn{9}{|c|}{ Vigor (\%) } \\
\hline & & \multicolumn{3}{|c|}{$\mathrm{EA}^{1}$} & \multicolumn{3}{|c|}{$\mathrm{EA}^{2}$} & \multicolumn{3}{|c|}{$\mathrm{EA}^{3}$} \\
\hline & & $48 \mathrm{~h}$ & $72 \mathrm{~h}$ & $96 \mathrm{~h}$ & $48 \mathrm{~h}$ & $72 \mathrm{~h}$ & $96 \mathrm{~h}$ & $48 \mathrm{~h}$ & $72 \mathrm{~h}$ & $96 \mathrm{~h}$ \\
\hline \multirow{4}{*}{ Maravilha } & 1 & $51 \mathrm{~d}$ & $3 \mathrm{c}$ & $0 \mathrm{c}$ & $92 \mathrm{~b}$ & $82 \mathrm{~d}$ & $63 \mathrm{c}$ & $60 \mathrm{c}$ & $12 \mathrm{~d}$ & $4 \mathrm{~d}$ \\
\hline & 2 & $62 a$ & $10 \mathrm{a}$ & $13 a$ & $96 a$ & $92 \mathrm{a}$ & $78 \mathrm{a}$ & $72 a$ & $24 \mathrm{a}$ & $14 \mathrm{a}$ \\
\hline & 3 & $58 \mathrm{~b}$ & $8 \mathrm{~b}$ & $8 \mathrm{~b}$ & $92 \mathrm{~b}$ & $90 \mathrm{~b}$ & $70 \mathrm{~b}$ & $64 \mathrm{~b}$ & $16 \mathrm{~b}$ & $10 \mathrm{~b}$ \\
\hline & 4 & $54 \mathrm{c}$ & $4 \mathrm{c}$ & $0 \mathrm{c}$ & $92 \mathrm{~b}$ & $84 \mathrm{c}$ & $64 c$ & $60 \mathrm{c}$ & $14 \mathrm{c}$ & $6 c$ \\
\hline CV (\%) & & 5,5 & 13,8 & 11,8 & 5,2 & 7,5 & 6,8 & 1,3 & 4,8 & 9,6 \\
\hline \multirow{4}{*}{ Verdinha } & 1 & $84 \mathrm{~b}$ & $36 a$ & $18 \mathrm{~b}$ & $96 \mathrm{~b}$ & $90 \mathrm{~b}$ & $84 \mathrm{~b}$ & $90 \mathrm{a}$ & $74 \mathrm{~b}$ & $58 \mathrm{~b}$ \\
\hline & 2 & $86 a$ & $36 a$ & $26 a$ & $100 \mathrm{a}$ & $95 \mathrm{a}$ & $90 \mathrm{a}$ & $90 \mathrm{a}$ & $82 \mathrm{a}$ & $72 \mathrm{a}$ \\
\hline & 3 & $62 \mathrm{~d}$ & $11 \mathrm{c}$ & $10 \mathrm{c}$ & $94 \mathrm{c}$ & $76 \mathrm{~d}$ & $76 \mathrm{~d}$ & $88 \mathrm{~b}$ & $66 \mathrm{~d}$ & $37 d$ \\
\hline & 4 & $82 \mathrm{c}$ & $22 b$ & $10 \mathrm{c}$ & $96 \mathrm{~b}$ & $88 \mathrm{c}$ & $80 \mathrm{c}$ & $88 \mathrm{~b}$ & $68 c$ & $48 \mathrm{c}$ \\
\hline $\mathrm{CV}(\%)$ & & 1,4 & 3,3 & 5,1 & 4,7 & 4,9 & 5,9 & 3,6 & 6,1 & 5,5 \\
\hline
\end{tabular}

Médias seguidas pela mesma letra na coluna não diferem entre si pelo teste de Tukey, $\mathrm{p} \leq 0,05 .{ }^{1}$ Teste de envelhecimento acelerado seguindo a metodologia tradicional, com água; ${ }^{2}$ Teste de envelhecimento acelerado utilizando solução saturada de $\mathrm{NaCl}$; ${ }^{3}$ Teste de envelhecimento acelerado utilizando solução diluída de $\mathrm{NaCl}$. 
Apesar da semelhança entre as informações proporcionadas por todos os procedimentos para as cultivares Maravilha e Verdinha (Tabela 4), indicando os lotes de menor e maior qualidade, o período de 48 horas de envelhecimento, empregando o procedimento tradicional, mostrou-se eficiente na separação de todos os lotes de cada cultivar em diferentes níveis de vigor. Nascimento e Pereira (2007b) também constataram que o período de 48 horas de envelhecimento de sementes de alface a $41{ }^{\circ} \mathrm{C}$ mostrou-se sensível, para estimar a qualidade fisiológica e o estabelecimento de relações com a germinação sob temperaturas adversas.

Neste estudo constatou-se que o período de 72 horas, para ambos os procedimentos modificados de envelhecimento, com solução saturada e diluída de $\mathrm{NaCl}$, também exibiu esta maior sensibilidade para a classificação dos lotes em diferentes níveis de qualidade fisiológica, quando comparado ao período de 72 horas do envelhecimento tradicional. Dessa forma, para a cultivar Maravilha, os lotes 2, 3, 4 e 1 apresentaram níveis decrescentes de qualidade fisiológica. Esses resultados concordam em parte com os obtidos para os testes de primeira contagem de germinação e emergência de plântulas em casa de vegetação quando indicam a inferioridade do lote 1 (Tabela 1). Os resultados da cultivar Verdinha indicam que os lotes 2, 1, 4 e 3 foram classificados em níveis de vigor decrescentes. Como os lotes 1 e 4 revelaram-se como de qualidade intermediária, houve, nesse aspecto, concordância com os resultados dos testes de primeira contagem e de emergência das plântulas (Tabela 1). Esse período de 72 horas de envelhecimento a $41{ }^{\circ} \mathrm{C}$, foi o utilizado por Franzin et al. (2004), em sementes de alface nuas e peletizadas mostrando-se eficiente para estratificar os lotes em função do vigor.

Verificou-se, de forma geral, que nesse caso a utilização do procedimento tradicional ou modificado do teste de envelhecimento acelerado possibilitou a obtenção de resultados semelhantes quanto à classificação dos lotes de sementes em relação a sua qualidade fisiológica. Porém, o procedimento utilizando solução salina, confirmando a constatação feita por Torres e Bezerra Neto (2009), apresentou uma vantagem em relação ao procedimento tradicional: o uso de soluções salinas em substituição à água reduziu o desenvolvimento de fungos, durante o teste, eliminando uma possível interferência na avaliação da qualidade fisiológica das sementes. Observações semelhantes também foram feitas por Costa et al. (2008), com sementes de couve, couve-brócolis e repolho.

Com relação às sementes de almeirão, no envelhecimento acelerado com solução salina (Tabela 5), observou-se redução da intensidade de captação de água pelas sementes durante o teste, de modo que, ao final dos períodos estudados, as mesmas atingiram graus de umidade uniformes e inferiores aos verificados com o uso do método tradicional. Constatou-se ainda que as sementes em contato com a menor umidade relativa, de $76 \%$, nitidamente perderam água durante o envelhecimento revelando que esta umidade relativa do ar associada à temperatura de $41^{\circ} \mathrm{C}$, mais elevada do que a do ambiente normal do laboratório, gerou uma condição de secagem da semente.

TABELA 5. Teor de água (TA) obtido após os períodos de envelhecimento, aos $41^{\circ} \mathrm{C}$, em sementes de almeirão das cultivares Catalonha e Pão-de-Açúcar.

\begin{tabular}{|c|c|c|c|c|c|c|c|c|c|c|}
\hline \multirow{3}{*}{ Cultivar } & \multirow{3}{*}{ Lotes } & \multicolumn{9}{|c|}{ TA $(\%)$} \\
\hline & & \multicolumn{3}{|c|}{$\mathrm{EA}^{1}$} & \multicolumn{3}{|c|}{$\mathrm{EA}^{2}$} & \multicolumn{3}{|c|}{$\mathrm{EA}^{3}$} \\
\hline & & $48 \mathrm{~h}$ & $72 \mathrm{~h}$ & $96 \mathrm{~h}$ & $48 \mathrm{~h}$ & $72 \mathrm{~h}$ & $96 \mathrm{~h}$ & $48 \mathrm{~h}$ & $72 \mathrm{~h}$ & $96 \mathrm{~h}$ \\
\hline \multirow{4}{*}{ Catalonha } & 1 & 8,3 & 18,3 & 16,2 & 7,1 & 8,5 & 5,5 & 6,2 & 7,5 & 7.5 \\
\hline & 2 & 9,1 & 14,4 & 14,3 & 7,2 & 8,3 & 5,3 & 6,2 & 7,6 & 7,4 \\
\hline & 3 & 8,4 & 17,3 & 16,5 & 7,3 & 8,2 & 5,5 & 6,3 & 7,5 & 7,7 \\
\hline & 4 & 10,5 & 15,4 & 14,1 & 7,1 & 8,1 & 5,4 & 6,4 & 8,5 & 7,5 \\
\hline \multirow{4}{*}{ Pão-de-Açúcar } & 1 & 5,9 & 15,1 & 16,8 & 6,6 & 5,6 & 5,7 & 8 & 8 & 7 \\
\hline & 2 & 8,6 & 11,2 & 12,9 & 4,5 & 5,7 & 6,6 & 7,9 & 9,3 & 6,9 \\
\hline & 3 & 5,6 & 13,3 & 11,8 & 5,6 & 6,8 & 5,7 & 7,9 & 7,9 & 7,9 \\
\hline & 4 & 6,7 & 12,1 & 10,7 & 4,7 & 5,8 & 5,6 & 9,1 & 7,8 & 8,1 \\
\hline
\end{tabular}

${ }^{1}$ Teste de envelhecimento acelerado seguindo a metodologia tradicional, com água; ${ }^{2}$ Teste de envelhecimento acelerado utilizando solução saturada de $\mathrm{NaCl} ;{ }^{3}$ Teste de envelhecimento acelerado utilizando solução diluída de $\mathrm{NaCl}$. 
Variação acima de 6,0 pontos percentuais foi observada entre o teor de água dos lotes de sementes após o teste de envelhecimento acelerado utilizando o procedimento tradicional (Tabela 5). Por outro lado, ao se empregar o procedimento modificado, essa variação não atingiu 1,0 ponto percentual. Isso evidencia maior uniformidade do teor de água das sementes ao se utilizar o procedimento modificado, o que já foi observado em trabalhos anteriores, com sementes de rabanete (Ávila et al., 2006).

$\mathrm{O}$ uso de solução saturada de $\mathrm{NaCl}$ proporcionou maior uniformidade e retardamento na absorção de água pelas sementes de almeirão. Desta maneira, as condições de envelhecimento com o uso de solução salina promoveram efeitos menos drásticos, pois ao atingir menores teores de água, o grau de deterioração das sementes foi atenuado em relação ao normalmente verificado com o uso do procedimento tradicional. Para sementes desta espécie, também não foi verificada a presença de fungos, com a adição de solução saturada de $\mathrm{NaCl}$. Observações semelhantes foram constatadas por Ávila et al. (2006), em sementes de rabanete e Nascimento et al. (2007a), em sementes de ervilha.

No presente trabalho foi possível classificar os lotes de sementes em níveis de vigor de forma eficiente a partir de 48 horas utilizando o procedimento tradicional e o modificado com solução diluída de $\mathrm{NaCl}$ e, somente a partir de 72 horas, utilizando o procedimento modificado com solução saturada de $\mathrm{NaCl}$ (Tabela 6).

TABELA 6. Germinação de sementes de almeirão, das cultivares Catalonha e Pão-de-Açúcar, obtidas após teste de envelhecimento acelerado, aos $41^{\circ} \mathrm{C}$, com três períodos de exposição.

\begin{tabular}{|c|c|c|c|c|c|c|c|c|c|c|}
\hline \multirow{3}{*}{ Cultivar } & \multirow{3}{*}{ Lotes } & \multicolumn{9}{|c|}{ Vigor (\%) } \\
\hline & & \multicolumn{3}{|c|}{$\mathrm{EA}^{1}$} & \multicolumn{3}{|c|}{$\mathrm{EA}^{2}$} & \multicolumn{3}{|c|}{$\mathrm{EA}^{3}$} \\
\hline & & $48 \mathrm{~h}$ & $72 \mathrm{~h}$ & $96 \mathrm{~h}$ & $48 \mathrm{~h}$ & $72 \mathrm{~h}$ & $96 \mathrm{~h}$ & $48 \mathrm{~h}$ & $72 \mathrm{~h}$ & $96 \mathrm{~h}$ \\
\hline \multirow{4}{*}{ Catalonha } & 1 & $86 \mathrm{~b}$ & $66 \mathrm{~b}$ & $66 a$ & $81 \mathrm{c}$ & $76 \mathrm{c}$ & $74 \mathrm{~b}$ & $83 \mathrm{~b}$ & $70 \mathrm{c}$ & $40 \mathrm{c}$ \\
\hline & 2 & $76 \mathrm{~d}$ & $44 \mathrm{c}$ & $60 \mathrm{a}$ & $92 \mathrm{~b}$ & $72 \mathrm{~d}$ & $70 \mathrm{c}$ & $76 \mathrm{c}$ & $62 \mathrm{~d}$ & $38 \mathrm{~d}$ \\
\hline & 3 & $78 \mathrm{c}$ & $66 \mathrm{~b}$ & $61 \mathrm{~b}$ & $80 \mathrm{c}$ & $80 \mathrm{~b}$ & $78 \mathrm{a}$ & $84 \mathrm{~b}$ & $80 \mathrm{~b}$ & $48 \mathrm{~b}$ \\
\hline & 4 & $88 \mathrm{a}$ & $74 \mathrm{a}$ & $66 a$ & $98 \mathrm{a}$ & $90 \mathrm{a}$ & $78 \mathrm{a}$ & $92 \mathrm{a}$ & $90 a$ & $56 \mathrm{a}$ \\
\hline $\mathrm{CV}(\%)$ & & 5,5 & 7,3 & 6,7 & 5,2 & 7,5 & 6,8 & 7,2 & 7,8 & 6,9 \\
\hline \multirow{4}{*}{ Pão-de-Açúcar } & 1 & $24 \mathrm{~b}$ & $22 \mathrm{a}$ & $14 \mathrm{~b}$ & $54 \mathrm{~b}$ & $58 \mathrm{~b}$ & $44 \mathrm{~b}$ & $68 \mathrm{~b}$ & $44 \mathrm{~b}$ & $4 \mathrm{a}$ \\
\hline & 2 & $18 \mathrm{c}$ & $20 \mathrm{~b}$ & $8 \mathrm{c}$ & $54 \mathrm{~b}$ & $55 \mathrm{c}$ & $48 \mathrm{a}$ & $58 \mathrm{c}$ & $36 \mathrm{~d}$ & $3 b$ \\
\hline & 3 & $34 \mathrm{a}$ & $22 \mathrm{a}$ & $16 \mathrm{a}$ & $62 a$ & $64 a$ & $48 \mathrm{a}$ & $72 \mathrm{a}$ & $64 \mathrm{a}$ & $4 \mathrm{a}$ \\
\hline & 4 & $12 \mathrm{~d}$ & $20 \mathrm{~b}$ & $6 \mathrm{~d}$ & $48 \mathrm{c}$ & $50 \mathrm{~d}$ & $44 \mathrm{~b}$ & $54 \mathrm{~d}$ & $48 \mathrm{c}$ & $2 c$ \\
\hline $\mathrm{CV}(\%)$ & & 6,8 & 5,8 & 7,0 & 4,8 & 6,2 & 5,3 & 7,3 & 7,7 & 6,8 \\
\hline
\end{tabular}

Médias seguidas pela mesma letra na coluna não diferem entre si pelo teste de Tukey, $\mathrm{p} \leq 0,05 .{ }^{1}$ Teste de envelhecimento acelerado seguindo a metodologia tradicional, com água; ${ }^{2}$ Teste de envelhecimento acelerado utilizando solução saturada de $\mathrm{NaCl}$; ${ }^{3}$ Teste de envelhecimento acelerado utilizando solução diluída de $\mathrm{NaCl}$.

O teor de água das sementes reduziu-se ou manteve-se inalterado no período de 96 horas em comparação ao de 72 horas nas metodologias modificadas (Tabela 5), embora a deterioração das sementes tenha aumentado em 96 horas de envelhecimento (Tabela 6). Partindo do princípio que a velocidade de deterioração aumenta com a elevação tanto do grau da umidade quanto da temperatura, considera-se que, nesse caso, a temperatura foi o fator predominante para a deterioração das sementes.
É possível constatar, através do teste de envelhecimento acelerado, que a cultivar Catalonha apresentou o lote 4 como de melhor qualidade, o lote 2 como de pior qualidade e os lotes 1 e 3 com qualidade intermediária. Os resultados da cultivar Pão-de-Açúcar indicam que os lotes 3 e 4 apresentaram melhor e pior qualidade, respectivamente, e os lotes 1 e 2 revelaram-se como de qualidade intermediária, havendo, nesse aspecto concordância com os resultados da avaliação inicial dos lotes de sementes. 


\section{CONCLUSÕES}

O teste de vigor, envelhecimento acelerado, conduzido a $41{ }^{\circ} \mathrm{C}$ é eficiente quanto à diferenciação de níveis de vigor em sementes de alface e de almeirão considerandose o período de envelhecimento de 48 horas pelo método tradicional ou o de 72 horas pelo método com solução saturada de $\mathrm{NaCl}$. Quanto ao método modificado pelo uso da solução diluída de $\mathrm{NaCl}$, o período de 48 horas é adequado para as sementes de alface e o de 72 horas, para as de almeirão.

\section{REFERÊNCIAS}

ÁVILA, P.V.; VILLELA, F.A.; ÁVILA, M.S.V. Teste de envelhecimento acelerado para avaliação do potencial fisiológico de sementes de rabanete. Revista Brasileira de Sementes, v.28, n.3, p.52-58, 2006. http://www.scielo.br/ $\mathrm{pdf} / \mathrm{rbs} / \mathrm{v} 28 \mathrm{n} 3 / 08 . \mathrm{pdf}$

BHÉRING, M.C.; DIAS, D.C.F.S.; VIDIGAL, D.S.; NAVEIRA, D.S.P. Teste de envelhecimento acelerado em sementes de pimenta. Revista Brasileira de Sementes, v.28, n.3, p.64-71, 2006. http://www.scielo.br/pdf/rbs/ v28n3/10.pdf

BRASIL. Ministério da Agricultura, Pecuária e Abastecimento. Regras para análise de sementes. Ministério da Agricultura, Pecuária e Abastecimento. Secretaria de Defesa Agropecuária. Brasília, DF: Mapa/ ACS, 2009. 395p.

CARVALHO, N.W.; NAKAGAWA, J. Sementes: ciência, tecnologia e produção. Jabotical: Funep, 2000. 588p.

COSTA, C.J.; TRZECIAK, M.B.; VILLELA, F.A. Potencial fisiológico de sementes de brássicas com ênfase no teste de envelhecimento acelerado. Horticultura Brasileira, v.26, n.2, p.144-148, 2008.
FERREIRA, D.F. Software Sisvar: Versão 4.6 (Build 6.0). Lavras: DEX/UFLA, 2003. Disponível em: < http://www. dex.ufla.br/danielff/prog.htm >. Acesso em: 6 maio 2010.

FRANZIN, S.M; MENEZES, N.L.; GARCIA, D.C.; ROVERSI, T. Avaliação do vigor de sementes de alface nuas e peletizadas. Revista Brasileira de Sementes, v.26, n.2, p.114-118, 2004.

JIANHUA, Z.; McDONALD, M.B. The saturated salt accelerated aging test for small-seeded crops. Seed Science and Technology, v.25, n.1, p.123-131, 1997.

MARCOS FILHO, J.; CICERO, S.M.; SILVA, W.R. Avaliação da qualidade das sementes. Piracicaba: FEALQ, 1987. 230p.

MARCOS FILHO, J. Testes de vigor: importância e utilização. In: KRZYZANOWSKI, F.C.; VIEIRA, R.D.; FRANÇA NETO, J.B. (Ed.). Vigor de sementes: conceitos e testes. Londrina: ABRATES, 1999. cap.3, p.1-24.

NASCIMENTO, W.M.; FREITAS, R.A.; GOMES, E.M.L.G.; SOARES, A.S. Metodologia para o teste de envelhecimento acelerado em sementes de ervilha. Horticultura Brasileira, v.25, n.2, p.205-209, 2007a.

NASCIMENTO, W.M.; PEREIRA, R.S. Testes para avaliação do potencial fisiológico de sementes de alface e sua relação com a germinação sob temperaturas adversas.

Revista Brasileira de Sementes, v.29, n.3, p.175-179, 2007b.

POWELL, A. A. The controlled deterioration test. In: VAN de VENTER, H. A. Seed Vigour Testing Seminar. Zurich: International Seed Testing Association, 1995. p.73-87. TEKRONY, D.M. Accelerated aging. In: VAN DE VENTER, H.A. (Ed.). Seed vigour testing seminar. Copenhagen: ISTA, 1995. p.53-72.

TORRES, S.B.; BEZERRA NETO, F. Teste de envelhecimento acelerado para avaliação do potencial fisiológico de sementes de urucum. Horticultura Brasileira, v.27, n.1, p.55-58, 2009. 